\title{
Creating A Positive Elementary Environment For Asperger Children
}

\author{
Mary Lee Batesko, (E-mail: bateskom@georgian.edu), Georgian Court University
}

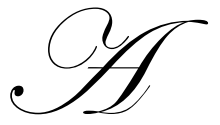

sperger's Syndrome is a neurological based disorder that primarily affects a person's ability to be successful with social relationships.Asperger's Disorder or Asperger's Syndrome is defined by the Diagnostic and Statistical Manual of Mental Disorders Fourth Edition (2000) as,

The essential features of Asperger's Disorder are severe and sustained impairment in social interaction and development of restricted repetitive patterns of behavior, interests, and activities. This disturbance must cause clinically significant impairment in social, occupational, or other important areas o functioning. In contrast to Autistic Disorder, there are no clinically significant delays or deviance in language acquisition (e.g., single nonechoed words are communicatively by age 2 years, and spontaneous communicative phrases are used by age 3 years), although more subtle aspects of social communication (e.g., typical give-and-take in conversation may be affected." (p. 80).

A study at Cambridge University is contemplating whether Isaac Newton and Einstein may have had Asperger's Syndrome. The disorder effects cognitive, sensory and communication skills. It is often considered a highly functional form of autism.

Often these children will become obsessive about one thing. It has been documented that Isaac Newton would prepare a lecture, proceed to the lecture hall, and if no one was present to hear his lecture, he would lecture to an empty room. Asperger children may obsess about models of cars, a horizontal line on the wall, music or just about anything. These children have average or above average intelligence and are often called "little professors". When changing from one subject to another or changing routines, these children have difficulty transitioning. They are oversensitive to stimuli and often have problems with organization, balance and coordination. They have superior vocabularies, may be anxious and depressed but their largest challenge is their lack social skills.

One might ask, how does one learn social behavior? Although there are many theories, the work of Albert Bandura believed a vital component was to observe and model the behaviors, attitudes and emotional reactions of others. Bandura (1977) states:

Learning would be exceedingly laborious, not to mention hazardous, if people had to rely solely on the effects of their own actions to inform them what to do. Fortunately, most human behavior is learned observationally through modeling: from observing others, one forms an idea of how new behaviors are performed, and on later occasions this coded information serves as a guide for action" (p22)

This modeling appropriate behavior stresses learning through observation and imitation. It is suggested that there are four sets of processes that govern how well a child will learn by observing another person. These processes are attention, retention, reproduction and motivation. Attention is based on the child's personal experience, personality characteristics, relationship with the model and situational variables. Retention is based on rehearsal, organization recall and other cognitive skills. Reproduction is based on cognitive representation, concept matching and use of feedback. Motivation is based on external incentives, internal incentives, internalized standards and social comparisons Teachers need to keep these concepts in mind when teaching all children but especially Asperser children.

There are several theories associated with AS. The predominant premise is the Behaviorist Theory. Maladaptive behavior is viewed as essentially the result of (1) a failure to learn necessary adaptive behaviors or competencies, such as how to establish satisfying person relationships or the learning of ineffective or maladaptive 
responses. (Butcher, Mineka, \& Hooley, 2004, p. 82). This maladaptive behavior fits AS students as it is common for them to be unaware that someone is irritated if the only clue is a frustrated facial expression. If they miss a social clue then they miss the lesson associated with the experience and will likely repeat the irritating behavior because they are unaware of its effects.

Although AS children are not aware of another's desires or emotions, the AS child is aware of his desires and emotions. This is useful in education if the instructor ascertains what is pleasing to the child and once the pleasure has been determined, the teacher can request the behavior and reinforce the behavior with the object of desire.

Also effective is applied behavior analysis and discrete trial training. By breaking learning down into small steps, each building upon each other, they ultimately lead to the overall concept. Since it is difficult for these students to sort through the different stimulus throughout the school day, applying ABA/DTT allows the student to focus on smaller quantities of information and possible the opportunity to complete an assignment rather than becoming overwhelmed.

Since social interaction presents a challenge to Asberger children, the teacher needs to create a positive classroom environment utilizing a social behavioral curriculum. Prior to achieving observational learning, the teacher should guide the student to organize and rehearse the modeled behavior and then enact it overtly. This modeled behavior should be coded into words, labels or images which will result in better retention than simply observing. If the individual values the outcomes, they are more likely to adopt the modeled behavior.

The teacher's behavior will have an effect on the Asperger child. She needs to be consistent, plan and execute a daily routine that follows the same pattern each day. If there is to be a change in the plans for the day, the Asperger child needs to know of the change in advance. Tasks in the classroom need to be structured so the Asperger child knows what to do.

The teacher needs to verbally discuss and model social skills because the Asperger child will not pick up the nonverbal clues. If the child reacts inappropriately, the teacher needs to offer alternative behaviors. She should never give the children an ultimatum. Also, the teacher needs to recognize and reinforce effort. Rather than say "You failed the test." A wise teacher would say "You did not pass the test, this time. However, there is always tomorrow". Since Asperger students are very sensitive, all unacceptable behaviors should be discussed in a nonjudgmental way.

Most Asperger children lack organizational skills, the teacher needs to assist them and help them be organized. Students should color code their books by getting different colored paper to cover the books and different colored folders to keep their work separated. For example, the social studies textbook would be colored green and the social studies homework folder would also be green. Likewise, the mathematics, spelling, and science books would all be color coded.

'The student should be provided with a daily assignment pad. Until organization skills improve, the teacher should record the assignments rather than the student. The student should have a map on his desk which relates to how his books are stacked in his desk.

The teacher should break down assignments into manageable components. As the student becomes more proficient with tasks, the teacher should gradually decrease the amount of structure provided the student.

Since Asperger children become easily frustrated by unexpected change, the teacher should attempt to maintain a consistent daily schedule which is written on the board each day. The daily routine needs to be planned and adhered to rather specifically. There should be initial success with frequent reassurance and positive feedback. 
Most Asperger children do not understand figurative language especially similes and metaphors. A classroom teacher needs to explain and assist the students in their understanding of figurative language. Asperger children take all information literally.

The classroom teacher needs to assist the student in understanding humor such as jokes or riddles. She should use direct explanation and many examples. The cliché "a picture is worth a thousand words" is especially true for Asperger children. Use pictures or photographs whenever appropriate and pictures where appropriate.

Three topics need to be considered in creating a positive classroom environment. The first is to teach the student how to interpret the social language of his peers and how to use social language in a variety of situations. Asperger children need to be taught to focus on the face for facial expressions and to take notice to body language. Second, many children with this condition do not understand the concept of taking turns. They need to be taught how to take turns in a game, discussion, or conversation. Finally, the students need to learn how to maintain the topic in a conversation and recognize when they do not understand. Finally, Asperger students need to know how to ask for clarification if they do not understand and how to provide clarification when his conversation partner does not understand the Asperger student.

Social interaction is important to AS children. When you consider the fire alarms, countless distractions, tours to the recess, lunch, gym and a bus ride to and from school all of which stress the AS child. For some children working as a team or in a group may be beneficial, but to the AS child it can be disaster.

To facilitate the reading process, a set period each day needs to be set aside for sustained silent reading. The teacher should provide many oral language activities especially those designed to increase listening comprehension as many of these students have difficulty attending to oral language activities. This may be helped by allowing the student to read books which hold their interest.

In the area of evaluation, the teacher should give immediate reinforcement for appropriate behavior. She should provide continual feedback to all children in the class so they are aware their performance is meeting the teacher's expectations. When dealing with an Asperger student, the teacher needs to be consistent. Also, the student should be aware of the consequences for appropriate and inappropriate behavior.

Since assessment is an ongoing process. Asperger Children must be continuously assessed in order for their behavior to be maintained. This assessment should be a class-by-Class observation. When assessment is and ongoing part of education it will be more likely to become natural and expected.

Assessment should not only be a collaborative, reflective process, but also multidimensional. Informal observation along with multiple tasks which would lead to a consistent pattern of performance.

When considering the right environment, sounds must be considered. Just as nails on the blackboard might effect many of us, the AS child is effected by sounds. Often having the child use headsets with soft music is helpful or ear plugs is another suggestion. Stressors can to a change in routine, sounds, moving about, class trip, etc. all of these may cause stress and inappropriate behavior

Asperger children should have a program which empowers them in all aspects of their education in addition to their social and emotional development. The classroom needs to focus on individual rather than external standards stressing the importance of being responsible for one's choices.

In order for Asperger students to develop better social skills, a social skills curriculum should be learner centered. This can be implemented in a constructivist-based cooperative learning environment that emphasizes hands-on, activity-based teaching and learning. Each student is viewed as a unique individual with different foundations of knowledge, which are based upon previous learning experiences. Instead of being a passive observer, actively participating in the learning process allows the student to apply new learning experiences to his/her existing knowledge base. 
Schools have traditionally emphasized rote learning and placed less emphasis on a holistic approach. Educational personnel need to recognize the importance of developing the student as a whole using the multiple intelligences defined by Howard Gardner.

Specific skills which should be taught include listening, asking for help, following instructions, completing assignments, contributing to discussions, ignoring distractions, setting a goal, beginning a conversation, expressing your feelings and recognizing another's feeling, using self-control, problem solving and finally accepting no.

Finally, a positive classroom environment, gives the Asperger student a sense of well-being. There is an array of positive school connections. The classroom is not only connected to the school but to the homes and parents in a positive way. Parents know their child's teacher and meet with the teachers often. The teacher keeps the parents informed regarding the student's progress.

\section{BIBLIOGRAPHY}

1. American Psychiatric Association. (2003). Diagnostic and Statistical Manual of Mental Disorders. Arlington, VA: American Psychiatric Association (p. 80).

2. Burcher,J., Mineka,S., \&Hooley, J. (2004). Abnormal Psychology. Boston, MA: Pearson Education, Inc.

3. Cox, Eileen, (1996), Why I Am Special, Boulder, Co: Career Track Publications

4. Health on Net, (October 17,2005) www.rardiseases.about.com/cs/aspergersyndrome. Einstein, Newton, and Asperger Syndrome.

5. Khslsa,SiriNam 5., (1999) Group Exercises for Enhancing Social Skills and Self-Esteem, Sarasota, FL:Professional Resource Press

6. Kirby, Barbara L.( 2005)www.udel.edu/bkirby/asperger/aswhatisit.html. What is Asperger Syndrome.

7. McGinnis, Ellen and Goldstein, Arnold, (1997) Skillstreaming the Elementary School Child: New Strategies and Perspectives for Teaching Prosocial Skills, Champaign, Illinois: Research Press.

8. $\quad$ www.aspennj.org/.(2005) Edison, NJ: Aspen Publications, What Is Asperger Syndrome?, 